\title{
Anthropometric analysis of wheelchair users: methodological factors which influence interpopulational comparison
}

\author{
Helda Oliveira Barros ${ }^{\mathrm{a},{ }^{*}}$ and Marcelo Márcio Soares \\ a Programa de Pós-graduação em Design, Universidade Federal de Pernambuco, Recife-PE, Brasil.
}

\begin{abstract}
This study identified the factors existing in the methods and techniques used in the anthropometric analysis of wheelchair users which may adversely affect inter-population comparisons. Five studies of anthropometric analysis of wheelchair users were examined: Nowak (1996), Jarosz (1996), Das and Kozey (1999), Kozey and Das (2004) and Paquet and Feathers (2004). All the selected studies presented intra- and inter-population data. After having identified the methods and techniques cited, a comparison was made between the procedures used by these authors and those adopted by Barros (2007). The results indicate that inter-population comparison is valid only when there is similarity between the procedures and techniques used to collect data and the functional characteristics of the people evaluated.
\end{abstract}

Keywords: anthropometric analysis, disable people

\section{Introduction}

Users of wheelchairs have special needs, requiring the optimization of the human-surroundings interface, with a view to reducing the human costs, based on the compatibility of the functional aspects with the usability requirements of the product. To do so, achieving an appropriate match by anthropometric means presents itself as an indispensable starting point $[3,4,7,8]$.

However, the paucity of anthropometric data on wheelchair users limits projects to create environments and products that can be used effectively and safely, and this also covers the concept of design [12-14].

On evaluating wheelchair users, the results enable important data on the population with disabilities to be gathered and also a comparison made between people with and without declared disabilities from the same region, and between distinct groups of disabled people.

This comparison is essential because it provides guidelines for designs better suited to the needs of these users. However, before comparing anthropometric data, it is necessary to compare selection methods and how samples were analysed.

Values found for populations of wheelchair users differ according to: the nature and degree of the physical disabilities, sample sizes and the decisions and techniques adopted for collection [2]. It is also important to note the positioning of the markers, the positions taken up in the sitting position and the types of dysfunction considered [10].

Finally, the authors Kozey and Das [6] caution that anthropometric, structural and functional, and interpopulation differences arise from:

1. General variations in body size;

2. Limitations imposed by the wheelchair;

3. Variation of objectivity and consistency in the measures and measurement techniques;

4. Variation in sample size;

5. Postural changes in the sitting position, typical of wheelchair users with a disability.

In this context, the objective of this study was to identify which factors existing in the methods and techniques used for the anthropometric analysis of

*Corresponding author. E-mail: helda_barros@yahoo.com.br 
wheelchair users may adversely affect interpopulation comparison.

\section{Methods and techniques}

In this study, five anthropometric studies of wheelchair users conducted by the following authors were analysed: Nowak [9], Jarosz [5], Das and Kozey [2], Kozey and Das [6] and Paquet and Feathers [5]. All the studies selected presented comparative intra- and inter-population data. After the methods and techniques cited had been identified, a comparison was made between the procedures used by these authors and those adopted by Barros [1], in 2007.

\subsection{Study undertaken by Nowak}

In 1996, Nowak adapted the method proposed by Das and Grady (1983 apud NOWAK, 1996), when analyzing ranges of motion on 2 planes: sagittal and transverse. The individuals evaluated were between 18 and 25 years old, and were all Polish.

For the transverse plane, the technique consisted of determining the radius of range by calculating a formula, in which the distance between the extremities of MMSS, glenohumeral in abduction to $90^{\circ}$, the measure referring to $1 / 2$ the depth of the trunk. This range was called MTR - Maximum Transverse Reach and encompassed the anterior and lateral reaches of the individual in the sitting position.

The pivot point was corresponding to an empirical selection of the possible, kinematic axis of the shoulder. And the length of the upper member was considered to be superior to the distance between the pivot point and the tip of the middle finger.

For the sagittal plane, the technique consisted of determining the radius of reach by calculating the difference between two structural measures, in is subtracted from the distance between the extremities of the MS, glenohumeral in flexion to $180^{\circ}$ [maximum point of reach superior until the seat] the measure referring to $1 / 2$ the depth of the trunk. This range was called MSR - Maximum Sagittal Reach, and encompassed the upper and lower ranges of the individual in a sitting position.

The anthropometric variables analysed were:

1. Height vertex-seat;

2. Depth of the trunk: anterior face of the trunk back;
3. Upper reach: glenohumeral flexion to $180^{\circ}$, distance tip of the middle finger - seat;

4. Anterior reach: glenohumeral flexion to $90^{\circ}$, distance tip from the middle finger - back;

5. Lateral reach: MMSS in horizontal abduction to $90^{\circ}$, half of the distance between the extremities of the middle fingers.

Nowak compared the data with a study she herself had done on Poles declared not have a disability. The result presented differences of up to difference of $30 \%$ in values found for the $5 \% \mathrm{IL}$ in the interpopulation comparison.

\subsection{Study undertaken by Jarosz}

Jarosz (1996) analysed 170 adult Poles, of whom there were 101 men and 69 women of working age between 18 and 39 years old. He used the method proposed by Das and Grady (1983 apud JAROSZ, 1996), modified by Nowak.

This study analysed only paraplegic individuals. Therefore, it excluded tetraplegic individuals and analysed people whose behavior was considered close to normal in the sitting position.

Foram analisadas as seguintes variáveis:

The following variables were analysed:

Height vertex - seat; Height eyes - seat; Height shoulders - seat; Height elbows - seat; Height of anterior side of knee - floor; Popliteal height: popliteal cavity - floor; Depth of the torso: anterior torso - back; Popliteal depth; Thickness of the thighs: upper side of the thigh - seat: Width of the shoulders; Width between the hips; Distance between the elbows; Upper reach: glenohumeral flexion to $180^{\circ}$; Distance tip of the middle finger - seat; Anterior reach: glenohumeral flexion to $90^{\circ}$; Distance tip of the middle finger - back; Lower reach: MS positioned along the body, distance seat - tip of the middle finger; Lateral reach: MMSS in horizontal abduction to $90^{\circ}$, half of the distance between the tips of the middle fingers; Distance between the middle fingers, with MMSS in horizontal abduction to $90^{\circ}$.

The individuals were evaluated in their own wheelchair, and they were asked to adopt their usual posture for their professional and everyday activities in the sitting position.

Although he did not explain the values, Jarosz (1996) presented a comparison with data from populations with and without declared disabilities and pointed to significant differences in the following measures: stature, thickness of the thighs, width 
between the hips, width between the shoulders and distance between the elbows.

Regarding reaches, he pointed out that $50 \% \mathrm{IL}$ of the people with disabilities is less than $5 \% \mathrm{IL}$ of those without a declared disability.

\subsection{Study undertaken by Das e Kozey}

In 1999, Das and Kozey evaluated 62 Canadians, of whom 42 were men and 20 women. The 62 subjects represent approximately 20 to $25 \%$ of the estimated population of Canadian wheelchair users.

The authors used digital photogrammetry, with the pictures being turned into slides, using the scale of half the real size of the body and the markers were typed manually.

17 structural variables were analysed:

Stature: vertex - floor; Height of the eyes: visual range envelope; Height of acromion - floor, Height of elbows: lower surface of the olecranon - floor: Height upper side of knee - floor; Height of the toes: upper side - floor; Height of the anterior range: $90^{\circ}$ flexion of the glenohumeral; Distance between the proximal phalanx of the middle finger - floor: Upper reach: $180^{\circ}$ flexion of the glenohumeral, interphangeal articulation of the middle finger - floor; NRA - Normal reach area: length of elbow - interphalangeal proximal of the middle finger; Length of acromion - proximal interphalangeal; Anterior reach: posterior side of trunk [height of the scapula] proximal interphalangeal; Depth of trunk; Bi-deltoid width; Bi-acromial width; Width between forearms: distance between the lateral points of the forearms /width of the armrest; Maximum depth: distance between the anterior and posterior distal points, from the chair or from the user; Height of seat.

Two cameras were used, which, to prevent parallax error, were positioned at two points: Sagittal $4.3 \mathrm{~m}$ and Frontal $-4.9 \mathrm{~m}$. According to the authors, it is important to consider the level and type of dysfunction presented by the individual. However, this consideration was limited to the clinical diagnosis, with no type of functional evaluation being conducted. The results found show that the measurements for men are greater than those for women.

\subsection{Study undertaken by Kozey e Das}

In 2004, Kozey and Das presented the new data on wheelchair users.

Citing the same population number of 62 adult Canadians, they used a 3-D method to analyse active membrane variables (dynamic anthropometry). The authors argue that 3-D methods allow a better understanding of the areas and volumes of the reaches that would be important to the process of creation.

The subject was asked to sit in his comfortable and normal working posture. He was placed in front of a workbench with the brakes of his chair on. A support was positioned on the back of the user's neck, at the C7-T1 level. The subjects were asked to maintain contact with the support while the normal and maximum ranges were being measured. So they were not allowed to make trunk movements. Individuals could move their shoulders.

The assessment was conducted at three different moments in time, with 1 min rest intervals between them:

$1^{\text {st }}$ Moment: Forearm + hand in contact with the bench;

$2^{\text {nd }}$ Moment: Moving the segment of forearm + hand from left to tight and vice versa comfortably without losing contact with the bench. The elbow should be maintained at an angle of approximately $90^{\circ}$;

$3^{\text {rd }}$ Moment: MS in extension, glenohumeral in flexion - abduction - external rotation.

They considered two points of reach:

NRA: Normal Area Reach - no ample movements of the glenohumeral joint, forearms semi-supported, without movement of the trunk.

MRE: Maximum Reach Envelope - total movement of the upper limb, torso stable.

According to the authors, these findings indicate that wheelchair users present $80 \%$ of the reach area described by Konz and Goel (1969 apud KOZEY, DAS, 2004) for people without a declared disability. The equivalent of a $75 \mathrm{~mm}$ reduction.

The maximum reach envelopes - MRE - were lower for wheelchair users. The difference, compared with the population that does not use wheelchairs, is greater for anterior reach than lateral reach. The authors consider that this difference is due to the fact that in studies conducted on those who do not have a declared physical disability were asked to adopt the upright posture while seated. This is not asked for from wheel-chair users, since it is more difficult for them to maintain themselves in an upright posture.

\subsection{Study undertaken by Paquet e Feathers}

In 2004, Paquet and Feathers evaluated 121 adult Americans, of whom 75 were men and 46 women. 
They used a 3-D method to analyse 21 (static) structural variables:

Abdominal depth: anterior side of the abdomen back; Height acromion - floor [right/left]; Biacromial width; Bi-deltoid width; Ankle width: medial malleolus medial - lateral [right/left]; Depth back - anterior side of the knee [right/left]; Depth of seat: back - popliteal side [right/left]; Height of armrest: elbow - floor [right/left]; Height of the eyes: envelope of visual reach [right/left]; Width between forearms: distance between lateral points of the forearms/width of the armrest; Width of the hand/handle: metacarpal II to V; Width between hips: distance between lateral points of the hips/width of the seat; Height of upper face of the knee - floor [right/ left]; upper face height of the knee - footrest [right/left]; Maximum depth: distance between the anterior and posterior distal points, from the chair or from the user; Stature: vertex - floor, Maximum width: distance between the anterior and posterior lateral distal points right - left; Height vertex - seat; Width between thighs/width of seat: Width of backrest; Height of the handles R/L: height of the handle of the wheel.

The authors state that the functional characteristics of individuals should be evaluated so that the differences are observed between populations of people with disabilities, but they do not describe any type of evaluation model.

They describe in detail the locations in which the markers are placed markers and believe that this information is essential for inter-population comparisons.

To conduct the experiment, the individuals were asked to maintain a relaxed posture in the sitting position, to abduct their shoulders and put their forearms on the support of their own wheelchair. According to the authors, the relaxed posture reduces the maximum height and bi-acromial width; in addition, it increases the bi-deltoid width, compared with the upright posture.

The results show that the intra-population differences reached $5 \mathrm{~cm}$. The authors state that despite differences being reported from a theoretical perspective, they constitute an important basis for biome- chanical and kinematic models, apart from providing essential information for the work of designers.

\subsection{Study undertaken by Barros}

For the anthropometric analysis, Digita was used, which is a digital photogrammetry system developed by the Department of Ergonomics at the Technical University of Lisbon - Portugal [11].

The study involved a random sample of 18 individuals, who used wheelchairs as a constant form of movement and were between 18 and 65 years old. The individuals were selected with the help of FCD the Portuguese acronym of an association which in translation is called the Christian Fellowship for the Sick and Disabled - an association that serves people with disabilities in the city of Recife.

Data collection took place in the Biomechanics Laboratory of the Maurício de Nassau Faculty, Recife, Pernambuco, which kindly donated the space in which to conduct this research study.

The research began with surveying the profile of the sample population, in which was recorded: age, gender, ethnicity and place of birth.

Next, the functional evaluation was conducted, which included: the clinical diagnosis, the history of the present illness, past medical history, articular examination, evaluation by movement and the examination of posture.

For the complete verification of the selected anthropometric variables, 11 photos were taken.

The 15 static anthropometric variables selected in this study were collected in four photos. The variables on the heights were first evaluated in a simple chair and then in a wheelchair, considering that the interference of the dimensions of the wheelchair generate new design needs.

The dynamic anthropometric variables were collected in 7 photos.

To better describe the standardization of the collection, the anatomical points used to reference each anthropometric variable are shown in the Table below. 
Table 1

Anthropometric variables

\begin{tabular}{|c|c|c|}
\hline & Anthropometric variables & Points of Reference \\
\hline \multirow{16}{*}{ 胥 } & Height of the top of the head & Top of the head - floor \\
\hline & Height of the level of the eyes & External corner of the eyes - floor \\
\hline & Height of the shoulder & Acromion - floor \\
\hline & Height of the knee & Anterior face of the knee - floor \\
\hline & Height of the popliteal cavity & Popliteal cavity - floor \\
\hline & Maximum depth of the thorax & Posterior side of the torso - anterior side of the thorax \\
\hline & Maximum abdominal depth & Posterior side of the torso - anterior side of the abdomen \\
\hline & Depth buttock - knee & Posterior side of the buttocks - anterior side of the knee \\
\hline & Depth buttock - popliteal cavity & Posterior side of the buttocks - articular line of the popliteal cavity \\
\hline & Length of upper member & Acromion - tip do middle finger \\
\hline & Length of arm & Acromion-olecranon \\
\hline & Length foream - hand & Olecranon - tip of the middle finger \\
\hline & Width of the thighs & Greater trochanter of the femur right to left \\
\hline & Width of the arms & Greater tubercle of the humerus right to left \\
\hline & Width of the thorax & Axillary line right to left \\
\hline & Anthropometric variables & Points of Reference \\
\hline \multirow{12}{*}{ 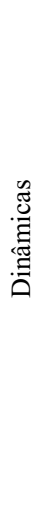 } & \multirow{3}{*}{ Anterior Reach } & A.1. Protraction of the shoulder \\
\hline & & A.2. Protraction of the shoulder + scapulo-humeral flexion to $90^{\circ}$ \\
\hline & & $\begin{array}{l}\text { A.3. Protraction of the shoulder }+ \text { scapulo-humeral flexion to } 90^{\circ}+\text { flexion of the } \\
\text { torso }\end{array}$ \\
\hline & \multirow{3}{*}{ Lower Reach } & I.1. Upper member extended, positioned along the body \\
\hline & & I.2. Upper member extended + depression of the shoulder \\
\hline & & I.3. Upper member extended + depression of the shoulder + inclination of the torso \\
\hline & \multirow{3}{*}{ Upper Reach } & S.1. Elevation of the shoulder \\
\hline & & S.2. Elevation of the shoulder + scapulo-humeral flexion to $180^{\circ}$ \\
\hline & & $\begin{array}{l}\text { S.3. Elevation of the shoulder + scapulo-humeral flexion to } 180^{\circ}+\text { maximum exten- } \\
\text { sion of the torso }\end{array}$ \\
\hline & \multirow{3}{*}{ Lateral Reach } & L.1. Lateral rotation of the scapula \\
\hline & & L.2. Lateral rotation of scapula + scapulo-humeral abduction \\
\hline & & $\begin{array}{l}\text { L.3. Lateral rotation of scapula }+ \text { scapulo-humeral abduction }+ \text { inclination of the } \\
\text { torso }\end{array}$ \\
\hline
\end{tabular}

\section{Results}

\subsection{Discussion and presentation of the results}

After identifying the methods and techniques used, the comparison was made between the procedures used in the six studies analyzed.

The comparative results are valid only when there is similarity between the procedures and techniques used in collecting data and the functional characteristics of those tested.

If the same individual were to be evaluated by all the authors cited, it is very likely that this would lead to distinct percentiles due to the variation of the type and degree of dysfunction evaluated.

For example, in the study by Barros [1], to the lowest percentiles equate to tetraplegic individuals, with very low degree of functionality. This does not happen in the Jarosz [5] study since the author considered only paraplegic individuals of productive working age between 18 and 39 years old. In general, we can say that the subject classified in the study of Barros and Smith as 5\% IL does not exist on the Jarosz scale, and the subject classified as as $5 \% \mathrm{IL}$ on the Jarosz scale would be equivalent to a much higher percentile, certainly above $50 \%$ IL on the scale defined by Barros. In addition, the Barros study considered an age group which goes up to 65 years old, so that the natural effects of aging were also considered.

Another important factor is the positioning of markers. When the anatomical reference points are different, the same anthropometric variable will present different results. In the study by Nowak [9], the length of the upper limb is calculated by the distance from the pivot point to the tip of the middle finger. This pivot point is the result of an empirical selection of the kinematic axis of the shoulder. In the Barros study, the acromion of the scapula was used 
as a reference. This simple change would generate important differences in the measures gathered by the authors. This means that if the same individual were evaluated in both studies, two different measures would be found for the same variable.

We must also notify the selection of external reference points. What is understood by external reference points are those that do not belong to the human body, such as floor, seat and backrest. In the Barros study, in order to define the start of the functional range, the acromion was used as a starting point and marked with a rod. Nowak and Jarosz begin to define the reaches from the seat of the wheelchair itself.

Another example is the evaluation of the height of the seated person. In the Barros study, this variable was defined as the distance from the top of the head to the floor because it was considered that this would be the real measure for minimum heights. The authors Nowak and Jarosz preferred to evaluate only the height of the segment head + trunk, so that they only consider the distance from the top of the head to the seat. These small variations certainly reflect differences in the measurements obtained, since each millimeter in anthropometric scales should be considered.

Continuing the discussion on the functional reaches, in the Kozey and Daz [6] study, the individuals could not perform movements with their trunk. They were asked to maintain contact with an apparatus located on the back of their necks such that they were to move only the upper limb. In the study by Barros, on the contrary, people were asked to move their trunk. Note that even if an individual is structurally taller, i.e. the length of the upper limb is greater, this can present a lower functional measure than that of someone else who may move their trunk.

The decision on the evaluation method is also extremely important. Nowak and Jarosz used a method of dynamic anthropometric analysis in which the measures of functional reach are obtained by subtractions of structural measurements. The lateral reach, for example, is obtained by calculating half the distance between the tips of the middle fingers, with the upper arms in horizontal abduction to $90^{\circ}$. As to Kozey and Das, they conducted the dynamic anthropometric analysis in a diagonal of combined movements of flexion, abduction and external rotation of the arm, generating a single action envelope which brings together the anterior, superior and lateral reaches.

Finally, the choice of chair will be discussed. Das and Kozey [2] and Paquet and Feather [10] evaluate the subjects in their own wheelchairs. All the authors acknowledge that the dimensions of the wheelchair affect the anthropometric measurements and that some dimensions vary by model and brand, but they did not use another type of support. In the Barros study, exactly because they agree with the authors, it was decided to carry out two instances of evaluation, with the simple chair and with the wheelchair. The data obtained in this study, arising from the repetition of the variables of height, show that the measures analysed in the simple chair are always smaller than those analyzed in the wheelchair.

Given there are so many differences, it can be affirm that the inter-population comparisons of the studies cited above are adversely affected.

\section{Final remarks}

In order to conduct inter- and intra-population comparisons, the factors described below need to be standardized so that the results are reliable.

\subsection{For structural and functional analyses}

In both types of analysis, with reference to static (structural measurements) or dynamic (functional reaches) anthropometry, the following items need to be considered:

1. Size of the sample;

2. Age interval of the subjects of the sample;

3 . Length of time using wheelchair;

4. Type of dysfunction and sequels, as well as the prior identification of the clinical diagnosis and the degrees of functionality. Taking into account that one functional limitation can be caused by different disabilities.

\subsection{For structural analyses}

Only for static analyses of anthropometry:

1. Posture adopted in the sitting position;

2.Interference of the dimensions of the wheelchair;

3. Positioning of the markers.

\subsection{For functional analyses}

Only for analyses of dynamic anthropometry:

Movements of the upper limbs and trunk permitted, during the tests of reach. 


\section{References}

[1] Barros, Helda Oliveira. Considerações sobre a Fotogrametria Digital - Sitema DIGITA - para a Análise Antropométrica de Usuários de Cadeira de Rodas. Recife: UFPE, 2007. $106 f$. Dissertação (Mestrado em Design) - Programa de Pósgraduação em Design, Universidade Federal de Pernambuco, Recife, 2007.

[2] Das, Biman. Kozey, John W. Structural anthrpometric measurements for wheelchair mobile adults. Applied Ergonomics, v. 30, p. 385 - 390. Editora Elsevier, 1999.

[3] FEENEY, R. The Ergonomics Approach to Inclusive Design Are the Needs of Disabled and Non-disable People Differente? VII Congresso Latino-americano de Ergonomia, I Seminário Brasileiro de Acessibilidade Intergral, XI Congresso Brasileiro de Ergonomia. Anais ABERGO 2002. Recife, 2002.

[4] Feeney, R. User-centred Design os Consumer Products and tha Enviromente with Particular Reference to the Needs of Older and Disable People. VII Congresso Latinoamericano de Ergonomia, I Seminário Brasileiro de Acessibilidade Intergral, XI Congresso Brasileiro de Ergonomia. Anais ABERGO 2002. Recife, 2002.

[5] Jarozs, Emilia. Determination of the workspace of wheelchair users. International Journal of Industrial Ergonomics, v. 17, p. 123 - 133. Ed Elsevier, 1996.

[6] Kozey, John W. DAS, Biman. Determination of the normal and maximum reach measures of adult wheelchair users. In- ternational Journal of Industrial Ergonomics, v. 33, p. 205 213. Editora Elsevier, 2004.

[7] Kumar, S. Perspectives in rehabilitation ergonomics. Londes: Ed Taylor and Francis, 1997.

[8] Kumar, S. Advances in Industrial Ergonomics and safety. Londres: Ed Taylor and Francis, 1992.

[9] Nowak, Ewa. The role of anthropometry in design of work and life anvironments of the disable people. International Journal of Industrial Ergonomics, v. 17, p. 113 - 121. Ed Elsevier, 1996.

[10] Paquet, Victor. Feathers, David. An anthropometric study of manual and powered wheelchair users. Industrial Journal of Industrial Ergonomics, v. 33, p. 191 - 204. Ed Elsevier: 2004.

[11] Rebelo, Francisco dos Santos. Sistema Digita - Aquisição de Dados Antropométricos Baseada em Técnicas Fotogramétricas para Aplicações em Ergonomia. Manual Técnico. Lisboa, Portugal, 2002.

[12] Soares, Marcelo Márcio. Translating User Needs Into Product Design for Disable People: a Study of Wheelchairs. Loughbrough: PhD, Loughbrough University, 1998.

[13] Soares, Marcelo Márcio. O design de produtos ergonômicos na melhoria da qualidade de vida dos usuários deficientes. ABERGO, 2000.

[14] Soares, Marcelo Márcio. Martins, Laura Bezerra. Design Universal e Ergonomia: uma parceria que garante a acessibilidade para todos. In: Adiel Teixeira de Almeida; Fernando M. Campello de Souza. (Org). Produção e Competitividade: aplicações e inovações; $1^{\mathrm{a}}$. Edição. Recife, PE: Editora Universitária UFPE, 2000, v.1, p. 127 - 156 